\title{
A GRAMÁTICA DE DAMOURETTE E PICHON COM LACAN: UMA PROBLEMÁTICA DA ENUNCIAÇÃO
}

\author{
Bruno Focas Vieira MACHADO*
}

- RESUMO: Esse artigo pretende evidenciar a importância específica conferida à gramática Des mots à la pensée: essai de grammaire de la langue française, de Damourette e Pichon (1943) para se pensar as bases lógicas do conceito de enunciação. Para cumprir esse objetivo, colocase a obra dos gramáticos em diálogo com elaborações da psicanálise, mais especificamente com conceitos de Jacques Lacan (2007). Busca-se, assim, uma interface entre os campos da linguística e da psicanálise, debruçando-se sobre a dicotomia existente entre os conceitos de sujeito da enunciação e sujeito do inconsciente. A abordagem tecida é eminentemente teórica, confrontando conceitos de cada pensador e buscando compreender os seus respectivos pontos de interseção. Para atingir esse objetivo, buscou-se o estudo sobre a negação em língua francesa elaborada pelos gramáticos Damourette e Pichon (1930) e colocou-a em relação com a dicotomia enunciado-enunciação construída por Lacan (2005) principalmente no Seminário 6: o desejo e sua interpretação. Como conclusão, torna-se claro como a gramática é inevitavelmente atravessada pela subjetividade e pelos fenômenos enunciativos.

- PALAVRAS-CHAVE: Sujeito. Enunciação. Linguagem. Inconsciente. Negação.

\section{A gramática de Damourette e Pichon em relação com a obra de Lacan}

A obra Des mots à la pensée: essai de grammaire de la langue française ${ }^{1}$ constitui uma vasta gramática redigida a quatro mãos por Jacques Damourette e Edouard Pichon. Consiste em sete extensos volumes que, segundo as informações colhidas por Arrivé (1999), formam um compêndio gramatical de uma amplitude que nenhuma outra língua além do francês jamais motivou. Cada um desses sete volumes está repleto de exemplos retirados do cotidiano, da literatura, de libretos de ópera, de diversos momentos diacrônicos da língua francesa, ainda de exemplos retirados da correspondência pessoal e da instrução de uso de aparelhos domésticos. Esse estilo carnavalesco e heterogêneo é coroado com um glossário dos termos específicos. Damourette e Pichon trabalharam intensamente nos volumes da gramática a partir de 1911, sendo que ambos viveram até a publicação do quinto volume.

* UFMG - Universidade Federal de Minas Gerais. Faculdade de Letras. Pampulha - Belo Horizonte - MG -Brasil. 31270-901 - b_machado@uol.com.br.

1 Das palavras ao pensamento: ensaio de gramática da língua francesa. 
Damourette e Pichon, respectivamente tio e sobrinho, foram uma dupla de gramáticos franceses que, a despeito de sua franca e eminente preocupação com os fatos mais propriamente da gramática, foram também linguistas membros da Sociedade de Linguística de Paris e, no caso específico de Pichon, igualmente um psicanalista. Na quinta lição do Seminário 6: o desejo e sua interpretação, Lacan (2005, p.58) se refere a Pichon como "um de nossos psicanalistas primogênitos". De fato, Edouard Pichon foi o primeiro linguista a se tornar psicanalista. De acordo com os sucintos dados bibliográficos levantados por Arrivé (1999), o tio Damourette, um filólofo, e o sobrinho Pichon, psiquiatra e psicanalista, faziam parte da Sociedade de Linguística de Paris e ali trabalhavam ativamente. Colaboraram também para a revista Français Moderne, que, naquele tempo, era um esboço de revista de linguística francesa; Pichon também publicou, no Journal de Psychologie, o artigo "A linguística na França." Ressalta-se o fato de que o termo psicologia, na época de Pichon, ainda não se referia à ciência da psicologia como se entende nos dias de hoje, sendo um termo amplo e difuso para se referir ao campo psíquico. Pichon, dessa forma, publicou um texto de linguística em um jornal que, segundo o título atesta, ocupava-se das questões do psiquismo, sendo um pioneiro na interface entre linguística e psicanálise. Pioneirismo semelhante também pode ser tributado aos gramáticos no que se refere à problemática da enunciação nos fatos de linguagem.

De acordo com a pesquisa levantada por Arrivé (1999), é relevante a informação de que Lacan e Pichon se conheceram e mantiveram relações, sendo o segundo um mestre a ser respeitado pelo primeiro. Isso dá uma tonalidade e peso diferentes na relação de Lacan com o eminente gramático, se comparada com a relação do mesmo Lacan com Freud, inteiramente mediada pela obra do pai da psicanálise. De acordo com o que se sabe e se tem registrado, Freud e Lacan jamais se encontraram pessoalmente. No que se refere aos aspectos da gramática de Damourette e Pichon adotados por Lacan, é possível se destacar a teoria da pessoa gramatical e a análise da negação em francês, sendo dessa última que Lacan buscará o conceito de forclusão para traduzir o termo freudiano Verwerfung e especificar o funcionamento do inconsciente na psicose. Esses dois aspectos da gramática de Damourette e Pichon incidem em Lacan sobre o mesmo ponto, como atesta Arrivé (1999), e a leitura do Seminário 6: o desejo e sua interpretação esclarece e evidencia: a questão e a problemática sobre o sujeito da enunciação.

Jacques Damourette, nascido em 1873, estudou arquitetura, mas, por limitações de saúde, não exerceu a profissão e se ocupou exclusivamente da linguística. Édouard Pichon, seu sobrinho 17 anos mais novo, estudou medicina, especializou-se em psiquiatria e teve contato com a psicanálise. Logo não é por acaso que Lacan parece ter um reconhecimento maior por Pichon do que 
por Damourette. Um exemplo muito notável desse fato pode ser encontrado no Seminário 3: as psicoses, na vigésima segunda lição. Lacan inicia sua lição evocando a gramática de dupla autoria de Damourette e Pichon, mas todos os seus posteriores comentários se focam exclusivamente no nome de Pichon. No início da lição número dezoito, Lacan (1985a, p.253), ao evocar a oposição entre pensamento e palavra, comparando-a com a oposição entre significante e significado, assim se expressa: "Alguém, um gramático sensacional, fez uma obra notável, na qual há apenas um erro, seu infeliz subtítulo, Das palavras ao pensamento." É curioso constatar que Lacan se refere à obra Das palavras ao pensamento, trabalhada e redigida a quatro mãos por Damourette e por Pichon, como possuindo uma única e singular autoria. Um dos autores é explicitamente omitido por razões aparentemente não explicadas. Ainda que não se possa afirmar com segurança qual dos dois é o "gramático sensacional" evocado por Lacan (1985), a leitura do seminário permite deduzir que se trata do nome de Pichon, e que Damourette é simplesmente desconsiderado como autor da obra nesse trecho. Semelhante fenômeno se repete na quinta lição do Seminário 6: o desejo e sua interpretação, no momento em que Lacan (2005) evoca a análise da negação em francês presente na gramática Das palavras ao pensamento. Estranhamente, Lacan (2005, p.58) atribuiu a autoria da análise da estrutura da negação e de seus componentes que são o forclusivo e o discordancial, apenas ao nome de Pichon, tratando-o inclusive por termos de grande reconhecimento, como notável, admirável e um de nossos psicanalistas primogênitos. Sobre essa questão, há um trecho que torna essas considerações ainda mais claras. Ao discorrer sobre Pichon e a análise da negação em francês, Lacan (2005, p.58) novamente se refere à gramática Das palavras ao pensamento como obra de sua autoria única:

Édouardo Pichon, a propósito da negação, fez essa distinção da qual é preciso que vocês tenham pelo menos um pequeno apanhado, uma pequena noção, uma pequena ideia. Ele percebeu alguma coisa, ele teria até desejado ser um lógico - manifestadamente queria ser psicólogo, ele nos escreveu que aquilo que faz é um tipo de exploração Des mots à la pensée.

Lacan (2005), propositalmente ou não, induz o leitor, no decorrer de toda essa específica lição, a acreditar que Des mots à la pensée e a análise da negação em francês são frutos unicamente da mão de Pichon. O único ponto que orienta o leitor é uma nota de rodapé logo após a citação reproduzida anteriormente, em que os tradutores especificam que a obra citada por Lacan (2005) possui a dupla autoria de Damourette e Pichon. A despeito do nome do primeiro ser omitido durante toda a quinta lição, Lacan (2005) abre a sexta lição dizendo que, da última vez, fizera alusão à gramática francesa de Jacques Damourette e de Édouard Pichon. Tal fato não deixa de soar como uma grande contradição por parte de Lacan. 
Retomando as relações travadas por Pichon com a psicanálise, Arrivé (1999) fornece outros dados que são importantes. O gramático foi um dos fundadores da Sociedade Psicanalítica de Paris em 1925 e foi presidente da mesma em 1938. No que toca a sua atuação como linguista, presidiu a Comissão Linguística para a unificação do vocabulário psicanalítico francês. Trata-se de outro fato que mostra claramente a maneira como Pichon transitava na interface Linguística e Psicanálise, antes de qualquer outro teórico e até mesmo Lacan fazê-lo. Uma curiosidade interessante a esse respeito foi seu esforço bem sucedido de, em 1927, impor ça como tradução para o termo freudiano es, em detrimento de soi. De fato, o ça se tornou um termo consagrado na literatura psicanalítica francesa, tendo sido inclusive adotado pelo próprio Lacan. Pichon ainda se ocupou, como demonstra Lacan (1985a, p.115) em partes do Seminário 3: as psicoses, da tradução para o francês das Memórias de um doente de nervos, autobiografia de Daniel Paul Schreber que serviu de ponto de referência para Freud (2010) teorizar a psicose paranoica: "Há os que em aparência vivem, se deslocam, seus guardas, seus enfermeiros, e que são sombras de homens atamancados às três pancadas, como disse Pichon, que está na origem dessa tradução."

\section{Des mots à la pensée e a dinâmica do inconsciente: a sissemia homofônica}

Esse espírito de vanguarda da dupla de gramáticos e, no que se refere especificamente ao diálogo com a psicanálise, não é observável apenas na interface teórica entre linguagem-psicanálise, mas também pode ser constatada na interface linguagem-inconsciente. A aproximação entre o inconsciente e a linguagem poética ou, como se expressaram Damourette e Pichon, entre o inconsciente e a utilização estética da língua, pode ser encontrada no capítulo Role de la phonétique en grammaire, ${ }^{2}$ pertencente ao primeiro volume de Des mots à la pensée. No entanto, simultaneamente, vê-se, nesse mesmo capítulo, um curioso tratado sobre a linguagem do inconsciente e a sua estrutura de palavra. Em Role de la phonétique en grammaire, a dupla de gramáticos propõe o conceito de "sissemia homofônica", criado por eles para denominar a "irressistível tendência" que têm os vocábulos homófonos a se confundirem e criarem uma ideia nova mais geral. Um exemplo dado entre vários é a homofonia entre as palavras raisonner (raciocinar, argumentar) e résonner (ressoar, retumbar) que, pelo seu caráter homofônico, podem se cruzar de diversas maneiras no espírito do locutor.

Sabe-se que o jogo de palavras e o cruzamento homofônico dos significantes é um dos princípios de linguagem descobertos no inconsciente por Freud (1987).

Função da fonética em gramática. 
Essa valorização do inconsciente em detrimento do consciente é partilhada por Damourette e Pichon (1930, v.1, p.160) que dizem: "Mais le plus souvent, la sysémie se fait sans intervention de la conscience."3 A sissemia, como grande parte das considerações expostas no decorrer de Des mots à la pensée, encontra seu fundamento no sentimento linguístico do falante da língua atual e não em razões puramente gramaticais. A sissemia homofônica, por essa razão, não opera quando o sentimento linguístico do falante não é chamado a perceber e produzir uma associação entre duas palavras homofônicas. Como exemplo, o que não deixa de ser contestável, eles argumentam que entre a terceira pessoa do presente do indicativo do verbo porter: il/elle porte (portar: ele/ela porta) e o substantivo feminino porte (porta), o falante não é chamado a se dar conta da homofonia, já que a ligação fonética é absolutamente diferente nos dois casos em que ela se mostra. O exemplo não pode ser tomado como verdadeiro, afinal é sabido que o falante e o inconsciente são capazes de produzir as associações mais inesperadas, mas o verdadeiramente importante é a preocupação de Damourette e Pichon em conduzir o problema da sissemia homofônica para o campo da semântica e do sentido, deslocando-o de considerações meramente gramaticais e fonéticas. Des mots à la pensée é um vasto compêndio de gramática que o tempo todo busca esse posicionamento paradoxal de se distanciar da própria essência da gramática e de se aproximar da semântica.

Prosseguindo, os diversos trocadilhos entre palavras homofônicas e sua imbricada rede de associação e de sentido, conforme expõem a dupla de gramáticos no prosseguimento do capítulo, são muito semelhantes à essência do chiste e dos atos falhos estudados por Freud (1969). Dessa forma, o princípio associativo dos significantes por metáfora no inconsciente é surpreendentemente ilustrado por Damourette e Pichon (1930, v.1, p.161) no prosseguimento de seu comentário sobre o termo porte:

Ce n'est en quelque sorte que par refléxion que l'on se rend compte que le mot porte (janua) se compose des mêmes phénomènes que le mot porte (fert). Et si, ayant pensé la suite phonétique porte comme corps de l'idée de janua, l'esprit vient, par association mécanique subconsciente, à voir surgir dans ce même corps l'idée de fert. ${ }^{4}$

Aqui os gramáticos parecem corrigir o que acabaram de afirmar e aceitam a existência de uma sissemia homofônica com porte por uma associação mecânica

3 Mas, de forma mais frequente, a sissemia se dá sem intervenção da consciência.

4 É somente por reflexão que alguém se torna ciente de que a palavra porta (janua) é composta das mesmas características da palavra porta (fert). Assim, ao se pensar o seguimento fonético porte como a matéria da ideia de janua, o espírito, por associação mecânica subconsciente, faz surgir nessa mesma matéria a ideia de fert [...] Obs: Janua é a palavra latina para porta ou entrada. Fert é a palavra latina que designa a terceira pessoa do presento do indicativo do verbo fero: portar, trazer. 
subconsciente. Eles aceitam, assim, a ideia genuinamente freudiana de uma associação metafórica de palavras no inconsciente ou, usando o termo trazido pelos gramáticos, no subconsciente. Essa associação mecânica subconsciente é descrita por Damourette e Pichon (1930) como experimentada no espírito do falante por uma sensação de brusca contradição, de mudança de perspectiva, de ser surpreendido por algo inesperado. A contingência e a surpresa, tão próprias das formações do inconsciente demonstradas pela associação livre, são apontadas como características da associação constituidora da sissemia homofônica, que, para aos gramáticos, também é inconsciente. Os gramáticos procedem em sua exposição fornecendo exemplos de trocadilhos entre palavras homofônicas que fazem lembrar a estrutura do Witz (chiste) proposta por Freud (1969) o que justifica Arrivé (1999) ter reconhecido em Damourette e Pichon uma indulgência quase freudiana para os trocadilhos.

Um dos exemplos expostos pelos gramáticos é a sissemia possível entre as palavras tant (tanto) e temps (tempo), ou ainda entre expressões como en tant (em tanto) e en temps (em tempo). Essa sissemina homofônica, de forma semelhante com as formações do inconsciente, obedece a uma essência lógica e apenas se aplica nos casos em que as palavras expostas estão regidas por tal regra. Exemplificando, a diferença de gênero, que para Damourette e Pichon (1930) é uma diferença taxiemática importante, é suficiente para impedir a sissemia, tal qual entre le somme (o sono) e la somme (a carga, o peso). Uma outra particularidade que impede a sissemia diz respeito às palavras homógrafas, porém não homofônicas, tais como la casse (tipo de frigideira, caçarola) e la casse (ação de quebrar, partir), ou ainda entre la manne (maná, alimento de origem divina) e la manne (tipo de cesto, berço). A regra lógica em questão para que a sissemia homofônica exista é, logo, o fato de as palavras em questão não englobarem cada uma por si só um sistema taxiemático intravocabular onde as mesmas possam se isolar. Essa regra lógica pode ser resumida dessa forma por Damourette e Pichon (1943, v.6, p.325): "La sysémie homophonique ne joue qu'à l'intérieur d'une même essence linguistique; et encore se meut-elle sur le domaine sémantique, psycholinguistique." 5 Pedese uma fluidez associativa, um pouco mais evidente que as associações linguísticas no inconsciente, para que esse interessante fenômeno estudado por Damourette e Pichon (1911-27) opere de maneira satisfatória. Arrivé (1999) não deixa de se perguntar se a sissemia homofônica constitui por si só um sistema linguístico, assim como o inconsciente é estruturado como um sistema linguístico.

A sissemia homofônica apenas ocorre no interior de uma mesma essência linguística e ainda se move sobre o domínio semântico, psicolinguístico. 


\section{A sissemia homofônica e a alíngua}

Uma possível definição para o termo lacaniano alíngua é compreendê-lo como uma linguagem tensionada pela função poética, ou nos termos de Lacan em Televisão, como o integral dos equívocos que a história de uma língua deixou persistir nela. A leitura atenta dos últimos seminários de Lacan a partir de Mais, ainda, seminário no qual a questão da alíngua é introduzida; assim como de seus textos mais tardios como Lituraterra, esclarece que a via privilegiada por Lacan (1985) para se ter acesso e praticar a alíngua é a própria homofonia, que desestabiliza as regras gramaticais da língua e os jogos de palavras dela resultantes. Encontra-se, então, uma visível intimidade entre os jogos de palavras e as rupturas de sentidos da alíngua descrita por Lacan e o fenômeno da sissemia homofônica descrita por Damourette e Pichon (1930). Essa intimidade é encontrada rumo ao final do capítulo "Role de la phonétique en grammaire", dedicado à sissemia homofônica. Os gramáticos novamente afirmam que a sissemia ou a tendência sissemímica não pertencem propriamente ao consciente e que ambas não são estranhas à utilização estética da língua. De acordo com a observação da dupla, todos os grandes poetas franceses ignoraram as leis do ritmo do verso francês, ainda que essa negligência não os tenha impedido de aplicá-lo com genialidade. Para os gramáticos, como o poder associativo dos segmentos fonéticos entram em jogo na poesia, esses não podem ser restritos estreitamente à lei da sissemia homofônica. Nesse momento de sua reflexão, Damourette e Pichon (1930) fornecem uma surpreendente articulação entre a linguagem poética e o inconsciente, provocando inevitáveis analogias com a poesia da alíngua no inconsciente:

Les suites phonétiques, les syllabes, les phonèmes même, ont, outre leur valeur onophonétique éventuelle, une valeur mnésique provenant de tous les mots desquels ils ont fait partie, et nous sommes persuadés que cette charge sémantique est constamment présente dans le subconscient du sujet parlant. C'est à travers ces éléments, que l'intellect conscient ne perçoit pas, que nous entrons em communion avec le génie du poète. (DAMOURETTE; PICHON, 1930, v.1, p.162, grifo do autor).

Essa passagem apresenta uma clara noção de um inconsciente estruturado como uma linguagem, lançando mão de um termo reconhecidamente freudiano, tal como valor mnêmico e de expressões com forte apelo lacaniano que são a carga semântica e o sujeito falante. A partir do momento em que se há afirma que há uma carga semântica no subconsciente do sujeito falante, termo dos gramáticos para se referir ao inconsciente, Damourette e Pichon (1911-27) reconhecem, bem anteriormente a Lacan, que o inconsciente é tecido de linguagem. 
No prosseguimento de seu raciocínio, a dupla de gramáticos evoca a carga semântica como via privilegiada para procurar o segredo do charme da rima. As articulações presentes no capítulo entre homofonia, inconsciente e linguagem poética parecem uma chave de leitura para localizar rudimentos do conceito de alíngua no texto de Damourette e Pichon (1930, v.1, p.163), sendo que a seguinte passagem é particularmente emblemática: " $C$ 'est également la charge sémantique qui permet de créer de nouveaux vocables tirés en apparence de néant." 6 Um dos pilares da noção de alíngua é a incidência de uma língua de gozo particular em cada sujeito que resiste à captura pelas normas compartilhadas de utilização da linguagem. A linguagem é, como se expressou Lacan (1985b) no Seminário 20, e a passagem citada de Damourette e Pichon também indiretamente evoca, uma constante elucubração de saber sobre essa invenção vocabular não compartilhada e aparentemente tirada do nada que é alíngua. É possível destacar uma passagem presente no Seminário 23: o sinthoma, em que Lacan (2007, p.129) comenta essa capacidade criadora da linguagem em sua relação com o inconsciente: "Criamos uma língua na medida em que a todo instante damos um sentido, uma mãozinha, sem isso a língua não seria viva. Ela é viva porque a criamos a cada instante." Damourette e Pichon (1930) parecem, décadas antes, ter percebido algo bastante próximo dessa afirmativa lacaniana que é fundamental para a noção de alíngua, preocupando-se, inclusive, com destacar o caráter imprevisível e inesperado da capacidade criadora da linguagem, cujos novos vocábulos são aparentemente tirados do nada.

\section{Damourette e Pichon com Lacan: a negação francesa e o discordancial}

Damourette e Pichon (1930) propõem abordar a problemática da negação por uma via que privilegia o sentimento linguístico do falante de língua francesa, sem deixar de lado a questão da subjetividade presente nos fatos gramaticais e nos fatos da própria língua. Trata-se de uma preocupação com a psicologia coletiva dos sujeitos que têm o francês como língua materna, servindo de uma expressão da dupla de gramáticos, que atravessa todos os sete volumes de Des mots à la pensée. A negação é uma base lógica de uma língua que se exprime na subjetividade e no campo psíquico de cada sujeito falante e que, como expressam Damourette e Pichon (1930), não é um fator real do pensamento francês. A dupla de gramáticos evidencia a peculiaridade da negação francesa por se constituída por duas partículas: a partícula ne que antecede o verbo a ser negado, e as partículas pas, rien, jamais dentre outras, que são colocadas após o verbo. Logo, em francês, não existe negação real, mas a combinação entre a discordância (ne) e a forclusão (pas, rien, jamais).

\footnotetext{
"É igualmente a carga semântica que permite criar novos vocábulos aparentemente tirados do nada."
} 
Sabe-se que a língua coloquial frequentemente omite o ne das assertivas negativas, o que permite concluir que a segunda partícula composta por termos como pas, rien e jamais seja mais próxima da negação bruta da lógica clássica que o ne. Para fornecer um exemplo bastante simples, uma frase como je ne sais pas (eu não sei) é frequentemente usada na linguagem oral como je sais pas (eu não sei) sem qualquer prejuízo para o sentido e para a força negativa presente na sentença. Compreender o ne originalmente como uma negação é, para a dupla de gramáticos, uma das noções mais elementares da gramática histórica do francês. A partícula ne, em francês arcaico, era de fato uma partícula negativa mas, devido à sua redução a um monossilábico e até mesmo apenas ao fonema [n], adquiriu-se o hábito de reforçá-la por meio de vocábulos de valor afirmativo, tais como pas, rien e jamais. Fatores históricos e diacrônicos retiraram paulatinamente da partícula ne seu valor negativo e a transportaram para a segunda partícula, sendo que, no francês atual, o ne possui um sentido completamente diferente da expressão de uma negação, que é a expressão de um discordancial. Para Damourette e Pichon (1943), o francês constitui todo um novo sistema taxiemático que substitui a negação latina, porém apontam que a explicação puramente histórica em nada esclarece a natureza das noções contidas nas partículas pas, rien ou jamais para a percepção linguística do francês contemporâneo. Essa natureza deve ser buscada na semântica da língua, em razões psicológicas do locutor, como já foi dito antes no que se refere à insuficiência da pesquisa histórica para a exposição dos fatos da língua.

Dando prosseguimento, há ainda dois empregos diferentes do ne em língua francesa: um deles é o ne conjugado com a partícula que, em que a única exceção à negativa é o substantivo introduzido na oração. Como exemplo, pode-se dizer je n'ai qu'um frère (eu tenho apenas um irmão). O terceiro tipo de emprego é o que mais interessou a Damourette e Pichon (1943), assim como também constitui o que de fato interessou a Lacan (2005) sobre a análise da negação e suas relações com o inconsciente. Há empregos isolados do ne em orações subordinadas, e foi esse tipo específico de emprego que levou a dupla de gramáticos a afirmar que o ne sempre expressava uma discordância entre essa subordinada e o fato central da frase. Devido a isso, foi por eles dado à partícula ne o nome de discordancial. Os exemplos são inúmeros em sentenças e situações mais discrepantes, razão pela qual se toma aqui o mais conhecido da língua francesa, o chamado ne éxpletif ${ }^{7}$ empregado em expressões que indicam temor, tal como je crains qu'il ne vienne. No exemplo em questão, a partícula aparentemente negativa ne expressa a discordância entre o sujeito da principal e a possibilidade que ele considera. Há aí uma divisão do sujeito na estrutura da linguagem, algo tão ressaltado e trabalho por Lacan (2005) em sua obra, sendo que o ne, ao contrário de exprimir

Ne expletivo. 
uma negação sintática, exprime o desejo do locutor de que ele não venha. Dessa forma, a tradução semântica correta para je crains qu'il ne vienne é eu temo que ele venha, e o ne opera apenas como elemento discordancial, não como partícula negativa. Lacan (2005, p.59) oferece uma interessante leitura para esse ne éxpletif no Seminário 6: o desejo e sua interpretação:

[...] alguma coisa no meu temor se antecipa ao fato de que ele venha e desejando que ele não venha, poder-se-ia de outra forma articular este "Eu temo que ele venha" ["je crains qu'il vienne"] como um "Eu temo que ele não venha" ["je crains qu'il ne vienne"] enganchando no caminho, ao passar, se assim posso dizer, esse ne de "discordância" que se distingue como tal na negação do ne forclusivo [forclusif].

Um segundo exemplo também interessante por denunciar a divisão subjetiva do falante na linguagem se encontra no uso do verbo désespérer (desesperar, afligir, perder a esperança). Coloca-se o discordancial após ne pas désespérer (não desesperar, não afligir, não perder a esperança), pois esse não exprime o oposto de désespérer, mas significa manter uma esperança pequena, o suficiente para que não haja desespero. Tal é o exemplo fornecido por Damourette e Pichon (1930, v.1, p.134, grifo do autor) "Que si... on travaillot encore à faire imprimer les livres grecs avec la traduction Françoise à costé, ce que je ne désespére pas que l'on ne fasse quelque jour [... [" ${ }^{8}$ No exemplo em questão, permanece, como concluem os gramáticos, uma discordância entre o desejo que se tem do acontecimento expresso na subordinada e a impossibilidade irredutível desse acontecimento.

\section{Damourette e Pichon com Lacan: o sujeito da enunciação e o discordancial}

Lacan (2005), na quinta lição do Seminário 6: o desejo e sua interpretação, inicia suas considerações tratando da duplicidade do significante entre o que é da ordem do processo do enunciado e do ato da enunciação. A distinção do sujeito Je da enunciação e do sujeito Je do enunciado é mais claramente ressaltada nas assertivas negativas, como já demonstrara Freud (2007) e a dupla de gramáticos Damourette e Pichon (1930). A negação, como expressa Freud (2007) em seu texto sobre a Verneinung, ${ }^{9}$ é um índice do recalque, de um não querer saber sobre uma simbolização primordial que recebe o nome de Bejahung. Assim, no exemplo tão conhecido trazido por Freud (2007, p.147), um paciente afirma a respeito de uma figura presente no relato de seu sonho: "Não é minha mãe." Freud (2007) é bem

\footnotetext{
8 "Que se... se trabalhasse ainda para mandar imprimir livros gregos com a tradução francesa ao lado, o que eu não perco a esperança que se faça algum dia [...]"

9 A denegação. Data original do texto: 1925.
} 
categórico ao dizer que, a respeito dessa frase, podemos desconsiderar a negativa da frase e considerar apenas o conteúdo, fornecendo uma interpretação que muito se aproxima das análises de Damourette e Pichon (1943) sobre a incidência do ne discordancial nas frases subordinadas: "É como se o paciente tivesse dito: Com relação a essa pessoa, de fato pensei na minha mãe, mas não tenho a menor vontade de deixar esta ideia valer." (FREUD, 2007, p.147). O conteúdo recalcado só pode advir à consciência com a condição de que seja negado e aceitado apenas no plano intelectual, sendo que a Verneinung é, ao mesmo tempo, um índice e uma supressão do recalque.

A trilha tomada por Lacan (2005) no Seminário 6 toma a direção de se evidenciar o absurdo, a contradição interna da função do "não". Ao se afirmar alguma coisa tal como "eu não digo", como ilustra o exemplo de Freud (2007), necessariamente se diz essa mesma coisa. Trata-se de uma propriedade estrutural do significante que é a de ser o sinal da presença de uma ausência. Lacan (2005), nesse momento, chama para a discussão a notável observação de Pichon sobre o sentido linguageiro da negação e sua distinção entre o discordancial e o forclusivo. Ao tratar sobre o ne puro, que oferece os problemas mais paradoxais para a negação, Lacan (2005, p.58) esboça um comentário que, mesmo involuntariamente, coloca Damourette e Pichon na via da Linguística da Enunciação: "O ne por si só, entregue a si mesmo, exprime o que ele chama uma discordância, e esta discordância é muito precisamente alguma coisa que se situa entre o processo da enunciação e o processo do enunciado." O ne éxpletif discordancial trabalhado por Damourette e Pichon (1943) é paradigmático para demonstrar que a discordância se situa entre enunciado e enunciação e é encarnada pelo ne. Arrivé (1999) ressalta que esse ne éxpletif é possivelmente o aspecto da língua francesa que mais insistentemente chama a atenção de Lacan e que mais o coloca na via do pensamento de Damourette e Pichon.

O sujeito da enunciação surge em diversos contextos da obra de Lacan reconhecido nesse ne éxpletif, dentre eles nos Seminários 3, 6, 7 e 9. A negação, para Lacan (2005), vai da enunciação ao enunciado, e isso vai de encontro com o fato de que toda negação no enunciado afirma alguma coisa para colocá-la ao mesmo tempo como não existente, uma não existência em algum lugar entre o enunciado e a enunciação. Rudimentos de uma teoria da enunciação podem assim ser encontrados na análise de Damourette e Pichon (1911-40) sobre o discordancial por se demonstrar que a discordância se encontra entre o enunciado e a enunciação. O ne ocupa, nas palavras de Lacan (2005), o lugar flutuante de uma certa errância entre o enunciado e a enunciação e demonstra sua própria discordância. Em contrapartida, se Lacan (1988, p.83) reconhece no ne o sujeito da enunciação, ele não deixa de o conduzir ao seu próprio sujeito da enunciação que é o sujeito do inconsciente: "A partícula negativa ne só aparece a partir do 
momento em que falo verdadeiramente, e não no momento em que sou falado, se estou no nível do inconsciente." Essa frase, retirada do Seminário 7: a ética da psicanálise, é consequência direta de um comentário da famosa sentença Je crains qu'il ne vienne, e que evidencia a importância desse ne para encontrar a distinção entre enunciado e enunciação. Lacan (1988, p.83) assim conclui de uma forma que parece de simples compreensão a maneira como o ne éxpletif designa o sujeito da enunciação:

Enunciando je crains... quelque chose, temo... alguma coisa, faço-o surgir em sua existência e, da mesma feita, em sua existência de voto - qu'il vienne, que ele venha. É aí que se introduz esse pequeno ne que mostra a discordância da enunciação com o enunciado.

O fato que surge no contexto dos seminários 3 e 6 se repete nesse ponto do Seminário 7, e o nome de Damourette é mais uma vez omitido por Lacan (1988, p.83), afirmando ele que o emprego tão sutilmente diferenciado desse ne discordancial na língua francesa se encontra no rastro de Pichon. Há ainda uma outra passagem pertencente ao Seminário 9: a identificação, trazida por Arrivé (1999) e importante de ser transcrita. Ela ressalta ainda mais a importância da gramática de Damourette e Pichon para o pensamento de Lacan e, mais propriamente, da noção do ne discordancial para consolidar a noção de sujeito da enunciação:

[...] je crains qu'il ne vienne não é tanto expressar a ambiguidade de nossos sentimentos do que, por essa sobrecarga, mostrar quanto, num certo tipo de relações, é capaz de ressurgir, emergir, reproduzir-se, marcar-se numa ausência, essa distinção do sujeito da enunciação, enquanto tal, em relação ao sujeito do enunciado. (LACAN apudARRIVÉ, 1999, p.146).

O ne discordancial, esse fenômeno particular da língua francesa tão bem encarnado nesse ne éxpletif, marca, assim, não apenas uma clivagem entre enunciado e enunciação, mas se encontra entre, no meio do caminho do processo da enunciação e o processo do enunciado. Ele liga, nas palavras de Lacan, a negação a um tipo de posição original da enunciação como tal e a própria negação se constitui como um gesto enunciativo sobre um enunciado já existente. Isso conduz a uma resposta, ainda que provisória para a questão posta por Lacan (2005) sobre a diferenciação entre o je da enunciação e o je do enunciado: se o sujeito da enunciação é o sujeito da enunciação inconsciente, é na dialética com o campo do Outro que se impõe a estrutura mesma da diferença entre enunciação e enunciado. A decomposição da estrutura do sonho, como faz Lacan (2005) no Seminário 6, ilustra bem essa proposição. Ao se comunicar um sonho, o sujeito dirige ao outro certo número de enunciados que comportam uma enunciação latente, que é a 
própria demanda de interpretação para esse sonho. Relatar um sonho é supor que esse sonho é significante e que seus enunciados possuem, assim, um índice de enunciação, pois fazer um relato é passar o sonho para o registro da linguagem. Aí entra, segundo Lacan (2005, p.65), o acordo ou a discordância, o acordo ou o desacordo entre a enunciação e o significante, entre o que é da relação no enunciado daquilo que está nas necessidades da enunciação:

O sujeito nos indica o quê? Um outro enunciado, mas não é nem um pouco suficiente dizer isso. De um outro enunciado que nos apresenta como uma enunciação, pois é um fato que o sujeito nos conta o sonho para que precisamente nós procuremos a chave, o sentido, isto é, aquilo que ele quer dizer, ou seja, para algo completamente diferente do enunciado que ele nos traz.

O sonho é, em si, essa outra cena, esse Outro absoluto do onde emana um enunciado suportado pela subjacência de uma enunciação presente no desejo sempre cifrado do sonho. Ao se dirigir a um outro a demanda de interpretação do sonho a partir do seu relato, a interpretação advém do próprio sujeito do inconsciente e cabe ao analista, ao contrário de um ouvinte cotidiano, permitir que essa enunciação inconsciente prevaleça. Curiosamente, um bom exemplo que trata da questão do sonho é trazido por Damourette e Pichon (1930, v.1, p.148) no capítulo sobre o discordancial, logo após afirmarem que o ne discordancial é a expressão do desgosto íntimo de ter de reconhecer um fato que se desejaria, consciente ou inconscientemente, que não houvesse ocorrido: "Néanmoins personne ne contestera que le rêve ne soit um phénomène psychologique."10

Em contrapartida, apesar dessas legítimas e inevitáveis aproximações, cabe manter certa distância entre a enunciação no sentido de Lacan (2005) e a enunciação no sentido dos linguistas. Se para ambos o sujeito da enunciação é o sujeito que fala, Lacan (2005) se esforçou para separar radicalmente as instâncias da enunciação e do enunciado, sendo que, nas teorias linguísticas, essa discordância expressa entre os dois termos não é tão observável: eles se conjugam a todo instante no discurso. É um posicionamento teórico semelhante àquele operado na dicotomia saussureana entre significante e significado: se para Saussure (2006) a barra indica que ambos estão associados, para Lacan essa mesma barra indica uma disjunção, essa tão extrema que o significante recebe um destaque diferenciado do significado. Essa aproximação entre a enunciação e o enunciado é o que Benveniste (2006, p.82), linguista da enunciação por excelência, adverte: "É preciso ter cuidado com a condição específica da enunciação: é o ato mesmo de produzir um enunciado, e não o texto do enunciado, que é nosso objeto." Além da enunciação se confundir com o próprio ato de produzir um enunciado,

10 Contudo ninguém contestará que o sonho seja um fenômeno psicológico. 
há nela, para Benveniste (2006), a dimensão de um ato individual de apropriação e utilização da língua por um sujeito. A ideia da existência de um agente da enunciação para Benveniste (2006) é bastante clara, pois para o linguista o ato da enunciação é o próprio fato do locutor mobilizar a língua por sua própria conta ao tomá-la como um instrumento.

Diferentemente, como indica Arrivé (1999), o sujeito da enunciação para Lacan é consequência da articulação significante no campo do Outro, não se configurando como agente, mas como um suporte. A enunciação lacaniana é aquela que encadeia a outra cena, como se expressava Freud (1972), onde se estruturam os significantes específicos que constituem o inconsciente. Eis o sentido a se dar ao axioma o significante representa o sujeito para outro significante, axioma que retira desse sujeito toda sua autonomia. Se a enunciação, nos termos de Benveniste (2006), implanta explícita ou implicitamente a dimensão de um outro (o alocutário) e é caracterizada pela acentuação da relação discursiva com o parceiro seja este real ou imaginado, individual ou coletivo; o parceiro do sujeito da enunciação de Lacan (2005) é apenas e exclusivamente o Outro do inconsciente. Como demonstra a análise do sonho apresentada no Seminário 6, o sujeito da enunciação se encontra com o sujeito do desejo, sendo que esse segundo é estranho e alheio ao universo das teorias linguísticas.

Um possível ponto de encontro entre o sujeito do desejo de Lacan (2005) com as teorias linguísticas é a própria análise do discordancial proposta pela gramática de Damourette e Pichon (1911-40), já que o ne expressa mais especificamente, nas palavras dos gramáticos, a discordância entre o desejo do sujeito da principal e a possibilidade que ele considera. Por esse caminho o sujeito do desejo de Lacan (2005) se encontra com o desejo do sujeito que é o elemento central da teoria gramatical de Damourette e Pichon (1911-40) sobre o ne discordancial. O desejo do sujeito aparece novamente um em comentário de Damourette e Pichon (1943, v.6, p.116) diretamente ligado à crainte (temor) e que se liga à disjunção entre o enunciado e a enunciação: "Des attitudes entraînant disordance, la plus passive est la CRAINTE, au sens plus général de ce terme. C'est une attitude psychologique dans laquelle il y a discordance entre ce que le sujet désire et ce que lui semble probable."11 Essa discordância entre o que parece provável e o que o sujeito deseja é uma questão que em muito interessa a dupla de gramáticos, sendo que a simples leitura demonstra o quanto isso ganha destaque em seu pensamento.

A expressão protestação disordancial do locutor também aparece como fundamento de uma explicação psicológica para o uso do discordancial, o que traz mais uma vez ao primeiro plano as dimensões do enunciado e da enunciação. O ne discordancial, fonte de uma infinidade de exemplos na gramática de Damourette

11 Dentre as atitudes de discordância, a mais representativa é a de TEMOR, no sentido mais geral do termo. Tratase de uma atitude psicológica na qual há discordância entre o que o sujeito deseja e o que o parece provável. 
e Pichon, tem para a dupla o estatuto de um órgão vivo semântico plenamente significativo, ao qual a língua recorre em todos os casos em que há uma demanda psicológica dos mesmos, e não em virtude de regras sintáticas puramente formais. O discordancial não necessita de uma conformação gramatical para se mostrar, ela se funda em uma motivação psicológica que emana do locutor. O termo fenômeno psicológico de fato aparece com bastante frequência diante dos exemplos do uso do ne discordancal em língua francesa. É ainda pertinente trazer uma outra passagem em que Damourette e Pichon evocam explicitamente a figura do locutor, termo muito frequente em Benveniste para se referir ao sujeito da enunciação, e a particularidade de cada um diante do discordancial:

Les cas dans lesquels le ne de la crainte est omis s'expliquent en partie par sa nature effective, certains locuteurs étant moins sensibles que d'autres au sentiment de discordance, mais peut-être en parti aussi par le préjugé que ce ne n'aurait pas de "valeur logique". ${ }^{2}$ (DAMOURETTE; PICHON, 1943, v.6, p.122).

Admitindo que a discordância não marca uma oposição intelectual, e sim o sentimento psicológico do locutor, torna-se mais clara a ideia de que o discordancial é comandado pelo sentido da frase e não por motivos meramente sintáticos. Longe de negar o fato, paradoxalmente a presença do ne confere um caráter de certeza a esse fato. Essas reflexões permitem uma melhor compreensão da forma como os processos de subjetividade e enunciação estão entranhados no próprio pensamento gramatical, desestabilizando a clássica divisão ente uma linguística hard e uma linguística soft. O pensamento gramatical, diferentemente do que pode a princípio parecer, não se furta de participar da constituição do sujeito da linguagem e da própria constituição do sujeito do inconsciente.

MACHADO, B. F. V. Damourette and Pichon's grammar, and Lacan's psychoanalysis: an utterance act issue. Alfa, v.56, n.1, p.309-324, 2012.

- ABSTRACT: This article intends to elucidate the specific importance of Damourette and Pichon's grammar Des mots à la pensée: Essai de grammaire de la langue française (1943) in order to think the logic basis of the utterance act notion. Accordingly, it fosters a dialogue between the grammarians' works and Jacques Lacan's psychoanalysis notions. It is thus pursued a link between linguistic and psychoanalytic fields by investigating the existing dichotomy between the subject of an utterance act and the subject of unconcious. The strictly theoretical approach brings the three authors' notions together and attempts to catch their intersection points by compiling the French negation studies in Damourette and Pichon's grammar and relating them to the dichotomy utterance/utterance act posited by Lacan's

12 Os casos em que o ne do temor é omitido se explica em parte por sua natureza efetiva, sendo certos locutores menos sensíveis que outros ao sentimento de discordância, mas talvez em parte também pelo preconceito de que esse ne não teria um "valor lógico". 
(2005) Seminar 6: desire and its interpretation. It concludes by stressing that both subjectivity and utterance act phenomena and grammar are interlaced.

- KEYWORDS: Subject. Utterance act. Language. Unconscious. Negation.

\section{REFERÊNCIAS}

ARRIVÉ, M. Linguagem e psicanálise, linguística e inconsciente: Freud, Saussure, Pichon, Lacan. Rio de Janeiro: Zahar, 1999.

BENVENISTE, E. Problemas de linguística geral II. Campinas: Pontes, 2006.

DAMOURETTE, J; PICHON, E. Des mots à la pensée: essai de grammaire de la langue fraçaise, 1911-1940. Paris: Ėditions d'Artrey, 1943. v.6.

. Des mots à la pensée: essai de grammaire de la langue fraçaise, 1911-1934. Paris: Éditions d'Artrey, 1935. v.4.

. Des mots à la pensée:essai de grammaire de la langue fraçaise, 1911-1927. Paris: Éditions d'Artrey, 1930. v.1.

FREUD, S. A negativa. In: de Janeiro: Imago, 2007. p.145-157.

Escritos sobre a psicologia do inconsciente. Rio

FREUD, S. A psicopatologia da vida cotidiana. Rio de Janeiro: Imago, 1987.

FREUD, S. A interpretação de sonhos. Rio de Janeiro, Imago: 1972.

FREUD, S. Os chistes e sua relação com o inconsciente. Rio de Janeiro: Imago, 1969.

LACAN, J. Seminário 23: o sinthoma. Rio de Janeiro: Zahar, 2007.

Seminário 6: o desejo e sua interpretação. Recife, 2005. Disponível em: <http://www.traco-freudiano.org/tra-lacan/desejo-interpretacao/0617dezembro1958.pdf>. Acesso em: 30 nov. 2011.

. Seminário 7: a ética da psicanálise. Rio de Janeiro: Zahar, 1988.

. Seminário 3: as psicoses. Rio de Janeiro: Zahar, 1985a.

. Seminário 20: mais, ainda. Rio de Janeiro: Zahar, 1985b.

SAUSSURE, F. de Curso de linguística geral. São Paulo: Cultrix, 2006.

Recebido em abril de 2011.

Aprovado em outubro de 2011. 